sex of the calves was reported. There was no significant deviation of the sex-rate from that of the corresponding control group.

In another series the centrifuge was run at 1,100 r.p.m., and the rate of flow $(16 \mathrm{ml} . / \mathrm{min}$.) of the suspension liquid was so high that only one-twentieth to one-fifteenth of the spermatozoa were retained in the centrifuge. They showed very low motility (overripeness ${ }^{a}$ ?). For this reason, and on account of the scantiness of spermatozoa, only 24 inseminations were performed with this material. Of the cows 12 became pregnant, all belonging to different herds. One cow had to be slaughtered later. The 11 calves were all males. In the corresponding control group of 9 calves, 3 were males and 6 fentales.

The last series of experiments is being repeated.

I am very much indebted to the Artificial Insermination Association of Enköping for allowing me to perform these experiments, and to the chief veterinarian, Dr. T. Svensson, and to Dr. K. Idla for most valuable co-operation. The counter-streaming centrifuge was run by Mr. P.- $\AA$. Lindström. Financial support from Ely Lilly and Co. is gratefully acknowledged. Per Eric Lindahl

Institute of Zoophysiology,

Upsala, Sweden. May 17.

${ }^{1}$ Lindahl, P. E., Nature, 161, 648 (1948). Lindahl, P. E., and Nyberg, E., Per. Sei. Eng. Res. (Stockholm), 26, 309 (1955).

${ }^{2}$ Makino, S., Cytologia (Japan), 13, 247 (1944).

${ }^{8}$ Lindahl, P, E., and Kihlström, J.-E., J. Dairy Sci., 35. 393 (1952).

${ }^{4}$ Phillips, P. H., and Spitzer, R. R., J. Dairy Sci., 29, 407 (1947).

\section{Blood-Histamine and Tissue-cell Anoxia in Mental Disease}

Work in our laboratories, inter alia, has been concerned for some years with the aberrant morph$\operatorname{ology}^{1}$ and physiological responses ${ }^{2-4}$ of the peripheral capillary vascular system of patients with schizophrenia and other mental disturbances. More recently, we have been concerned with the effects of these responses of the minute vasculature on the oxygenation of the adjacent tissue cells. In brief, wo have found that, under conditions of increased capillary pressure, lessened local blood-oxygen satura. tion and capillary corpuscular flow (often with intravascular erythrocytic agglutination), hydration, swelling, vacuolization, granularity and other degenerative changes reminiscent of cellular cloudy swelling occur progressively in the intervascular tissue substance ${ }^{5}$. These changes reverse themselves when the vascular conditions seemingly csusing them also suffer a reversal. Although these changes have been observed from time to time in healthy subjects, they are much more characteristically seen, and for much longer periods of time, in psychiatric patients, and especially in psychotics. Also, these vascular and cellular responses seem to coincide in time with significant happenings in the mental state of the patients and the dynamic variations occurring in their state of consciousness (for example, a worsening of the pathophysiology takes place when hallucinations are experienced ${ }^{6}$ or when a myoclonic seizure ${ }^{7}$ occurs in an epileptic, while an improvement in these reactions coincides with recovery or subsidence of these events).

Our interest in the mechanism whereby the cell could conceivably be affected by a diminution in the supply of molecular oxygen in the capillaries led to a study of the histamine metabolism of psychiatrie patients. Using the Lowry et al. ${ }^{8}$ column chromatographic microchemical method of estimating blood histamine (modified by trebling the concentration of DNFB per aliquot) and 5-ml. blood samples obtained by venupuncture, we investigated both mentally healthy and mentally sick populations all in the non-fasting state. In the former $(N=12)$ we found a mean blood histamine-level of $88.86 \gamma$ per litre $(s=27 \cdot 43)$, that is, very close to the mean of $82 \cdot 0 \gamma$ per litre for 'true' histamine reported by Lowry et al. and the figure of $86 \gamma$ per litre obtained by Valentine et al. ${ }^{2}$ from 16 non-fasting healthy subjects using Code's ${ }^{10}$ modification of the original Barsoum and Gaddum ${ }^{11}$ bioassay technique. In the latter population the mean levels were invariably greater, those for schizophrenia $(N=29)$ being $106 \cdot 38 \gamma(s=24 \cdot 84)$ and contrasting with those for epilepsy $(N=5)$ at $139 \cdot 42 \gamma$ per litre $(s=24 \cdot 57)$, while those for other psychiatric conditions $\left(N_{T}=66\right)$ lay between these two values. An analysis of variance showed the differences between the means to be significant $(P=0.01)$ and no significance could be attached to the possible variables of age and sex.

If these results are confirmed, their repercussions on stress-theory and on the role of histamine metabolism in this theory will be considerable; as they stand they strengthen the growing evidence favouring the relationship between tissue anoxia, mental disease and histamine release. We are currently engaged in extending our experiments in a longitudinal fashion in an endeavour kinetically to correlate the precise vascular and tissue events in circumstances of changing concentrations of blood histamine. The results contained in this communication will be published in greater detail in specialist journals elsewhere.

\section{J. W. LovetT Doust \\ H. HUSDAN \\ M. E. SALNA}

Research Laboratories,

Department of Psychiatry, University of Toronto. June 21.

${ }^{1}$ Lovett Doust, J. W., J. Nerv. Ment. Dis., 121, 516 (1955).

2 Lovett Doust, J. W., J. Clin. Exp. Psychopathol., 16, 272 (1955).

${ }^{3}$ Lovett Doust, J. W., Arch. Neurol. Psychiat., 74, 137 (1955).

${ }^{4}$ Lovett Doust, J. W., J. Ment. Sci., 88, 143 (1952).

- Lovett Doust, J. W., and Salna, M. E., Canad. Psychiat. Assoc. J. 1,35 (1956).

- Lovett Doust, J. W., and Salna, M. E.. Canad. Med. Assoc. J., 72, 803 (1955)

'Lovett Doust, J. W., and Schneider, R. A., J. Mental Sci., 88, 640 (1952). B Lowry, O. H., Graham, II. T. Harris, F. B., Priebat, M. K., Marks,
A. R., and Bregman, R. U., J. Pharmacol. Exp. Therap., 112, 116 (1954).

- Valentine, W. N., Pearee, M. L., and Lawrence, J. S., Blood, 5, 623 (1950).

${ }^{20}$ Code, C. F., J. Physiol., 89, 257 (1937)

${ }^{21}$ Barsoum, G. S., and Gaddum, J. H., J. Physiol., 85, 1 (1935).

\section{Detection of Xanthine Dehydrogenase Activity in Soluble Proteins of Rat Liver separated by Paper Electrophoresis}

IT has been shown by paper electrophoresis that xanthine dehydrogenase activity is bound to the globulin fractions of rat serum ${ }^{1}$. Using differential centrifugation, it was demonstrated that xanthine oxidase and xanthine dehydrogenase activities are present in the supernatant fluid corresponding to the 'cellsap' containing the soluble proteins of the rat liver ${ }^{2}$.

A large number of proteins are present in the 'cell sap' fraction of the rat liver, and they have recently been separated by paper electrophoresis ${ }^{3}$. We were 